\title{
CARDIAC PAIN IN ASSOCIATION WITH MITRAL STENOSIS AND CONGENITAL HEART DISEASE \\ BY
}

\author{
DOUGLAS STUCKEY* \\ From the Institute of Cardiology, National Heart Hospital \\ Received November 3, 1954
}

The association of angina pectoris with mitral stenosis has interested cardiologists for many years. The first reference seems to be that of Nothnagel (1891) who found anginal pain in 18 per cent of his patients with mitral stenosis. There have been many case reports since that time of angina pectoris occurring in young subjects with mitral stenosis (Graham Steel, 1906; Hirschfelder, 1910; Sternberg, 1923; Telia, 1925; Hochrein, 1930; Scherf and Goldhammer, 1933; Parker and Weiss, 1936), and in a number of instances normal coronary arteries were revealed at necropsy. For example Blackford (1940) reported two such cases with severe mitral stenosis and normal coronary arteries and found seven previously reported cases in which the results of necropsy were available, and 25 other case reports since 1923. Burgess and Ellis (1942) considered that true angina pectoris was rare with mitral stenosis and confined to older patients, and discussed socalled "hypercyanotic angina" occurring in long attacks unrelated to effort. Levine and Kauvar (1942) studied 38 patients with mitral stenosis and angina pectoris: three were under the age of 40 years, and women predominated over men in the proportion of $2: 1$. The average age of onset of angina was 50 years for the women and 54 years for the men. The incidence of angina pectoris among 741 patients with mitral stenosis was 2.6 per cent. In sixteen of their patients the results of necropsy were available; in three of these the coronary arteries were normal. Significant disease of the coronary arteries was found post-mortem in only 5 per cent of 314 cases of mitral stenosis. They concluded that in the majority of such patients mitral stenosis and coronary artery disease merely coexist. This has been the general opinion since that time, and is quoted in most textbooks.

The impression that aortic incompetence is the only valvular lesion commonly associated with angina pectoris in young subjects, seems to date from papers by White and Mudd (1927) and by Schwartz (1927). Most of the thirteen patients mentioned by these authors had mitral valve disease as well, and there was no post-mortem confirmation.

References to the occurrence of angina pectoris in patients with congenital heart disease are more scanty. Aortic stenosis has only recently been considered a relatively common congenital condition (Campbell and Kauntze, 1953), but the association of angina pectoris with this lesion is well recognized, and it occurred in 11 of the 40 patients reported by these authors. Friedberg (1949) put the incidence of angina of effort in patients with aortic stenosis at 10-20 per cent, perhaps more if specific enquiry is made for the symptom, and quoted his own earlier work (Friedberg and Horn, 1939) demonstrating acute myocardial damage and normal coronary arteries at necropsy in patients with aortic stenosis who had died suddenly. Isolated cases have been reported of angina pectoris occurring in patients with atrial septal defect (Bedford et al., 1941; Viar and Harrison, 1952), the tetralogy of Fallot (Blackford, 1930; Dow et al., 1950), pulmonary stenosis (Lowance et al., 1948; Wood, 1950; Abrahams and Wood, 1952), transposition of the great vessels (Astley and Parsons, 1952), and Eisenmenger's complex or patent ductus arteriosus (Viar and Harrison, 1952).

The association of angina pectoris with pulmonary hypertension was first described by Vaquez

${ }^{*}$ Holding a Nuffield Foundation Travelling Fellowship in Medicine. 
and Giroux (1908), who coined the phrase "angine pulmonaire hypercyanotique" to describe a clinical syndrome associated with pulmonary vascular abnormalities and lung disease. Posselt (1908), Frugoni (1911), Arillaga (1913), and Engelen (1923) reported similar cases. Brenner (1935) described a boy, aged 11 years with anginal pain, in whom necropsy revealed primary pulmonary arteriosclerosis and gross hypertrophy of the right ventricle, and suggested that the pain was due to myocardial anoxia associated with arterial anoxæmia. Brill and Krygier (1941) found that chest pain of anginal type had been described in 4 of 20 reported cases of primary pulmonary hypertension including one of their own, and suggested that it might be due to coronary insufficiency associated with diminished systemic blood flow through an obstructed pulmonary circulation. Wood (1950) found angina in three of six patients with idiopathic pulmonary hypertension. Viar and Harrison (1952) described six patients with chest pain associated with pulmonary hypertension, three of them with emphysema, one with atrial septal defect, one with mitral stenosis, and one with massive pulmonary embolism: necropsy in three showed normal coronary arteries. They described the pain as identical clinically with angina pectoris but perhaps lasting longer, often accompanied by dyspnœa, and relieved by the administration of oxygen or aminophylline but not by trinitrin. They suggested that the pain was due to distension of the pulmonary artery.

A number of cases were encountered of classical angina of.effort in young subjects with congenital heart lesions or with mitral stenosis. It was decided to investigate both these groups of patients, hoping that the one might throw some light on the other. The congenital group provides such a wide range of variation in blood flow, in pressures in various chambers and vessels, and in arterial oxygen saturation, that it was hoped some explanation might be found for cardiac pain occurring in the absence of coronary artery disease.

\section{Mitral Stenosis}

A brief report of the conclusions reached in regard to patients with mitral stenosis suffering from angina pectoris has been given by Wood (1954). The patients selected were those giving a classical story of angina of effort identical with that given by older patients with coronary artery disease, except that the chest pain was often accompanied or preceded by breathlessness, and when provoked by effort sometimes persisted for as long as ten minutes before being relieved by rest. The many other types of chest discomfort found in patients suffering from mitral stenosis have been excluded.

Amongst 400 patients with mitral stenosis, angina pectoris occurred in $34(8 \%)$, and the details are shown in Table I. The female to male ratio was 4.7:1, and the average age 37 years for the women and 33 years for the men. The age and sex incidence of uncomplicated ischæmic

TABLE I

Incidence of Angina Pectoris in Patients with Mitral Stenosis

\begin{tabular}{|c|c|c|c|c|c|}
\hline Group & Condition & $\begin{array}{l}\text { Number } \\
\text { in group }\end{array}$ & $\begin{array}{l}\text { Angina under } \\
\text { the age limits* }\end{array}$ & $\begin{array}{l}\text { Angina over } \\
\text { the age limits* }\end{array}$ & $\begin{array}{l}\text { Angina at } \\
\text { all ages }\end{array}$ \\
\hline $\begin{array}{l}\text { II } \\
\text { III } \\
\text { IV }\end{array}$ & 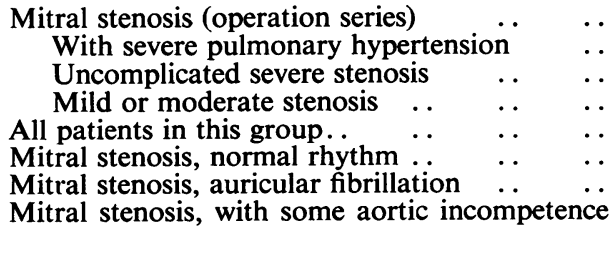 & $\begin{array}{c}29 \\
37 \\
34 \\
100 \\
100 \\
100 \\
100 \\
(30 \text { A.F.) }\end{array}$ & 8 (2 $\begin{array}{c}4 \\
4 \\
7 \\
7 \\
2 \\
4\end{array}$ & $\begin{array}{c}1 \text { (A.F.) } \\
4 \\
7 \\
1\end{array}$ & $\begin{array}{r}9 \\
11 \\
9 \\
5\end{array}$ \\
\hline & Mitral stenosis, all patients reviewed $\ldots$ & 400 & $21(5 \%)$ & $13(3 \%)$ & $34(8 \%)$ \\
\hline
\end{tabular}

A.F. Auricular fibrillation.

* In men, under 35 years of age; in women, under 37 years of age. 
heart disease studied at the same hospital over the same period of time (Stuckey), 1955, rendered it most unlikely that coronary atherosclerosis played a significant part in the production of cardiac pain in men aged under 35 years or in women under 37 years.

There were 21 patients under these age limits with mitral stenosis and angina pectoris, and some details are recorded in Table II. The pulse was of small volume in 19: the blood pressure was normal or low, with two exceptions in which the systolic pressure was $170 \mathrm{~mm}$. $\mathrm{Hg}$. Hæmoglobin values were within the normal range.

TABLE II

Patients with Angina Pectoris and Mitral Stenosis

\begin{tabular}{|c|c|c|c|c|c|c|c|c|c|c|c|}
\hline $\begin{array}{c}\text { Case } \\
\text { No. }\end{array}$ & Age & Sex & Diagnosis & & Rhythm & $\begin{array}{c}\text { Systemic } \\
\text { B.P. }\end{array}$ & $\begin{array}{l}\text { P.A. } \\
\text { pres- } \\
\text { sure }\end{array}$ & $\begin{array}{l}\text { L.A. } \\
\text { pres- } \\
\text { sure }\end{array}$ & $\begin{array}{c}\text { Cardiac } \\
\text { output }\end{array}$ & $\begin{array}{c}\text { Pulm. } \\
\text { resist- } \\
\text { ance }\end{array}$ & Valve size \\
\hline 1 & 32 & $\mathrm{~F}$ & M.S. (T.S.), P. H.* & & N. & $170 / 80$ & $90 / 45$ & 15 & $2 \cdot 3$ & 21 & Slit $0.5 \mathrm{~cm}$. \\
\hline 2 & 27 & $\mathrm{~F}$ & M.S. (T.I.), P. H. & & N. & $120 / 80$ & $90 / 40$ & 20 & $2 \cdot 7$ & 17 & Slit $0.6 \mathrm{~cm}$. \\
\hline 3 & 36 & $\mathrm{~F}$ & M.S., P. H. & .. & N. & $110 / 76$ & $90 / 45$ & 30 & $2 \cdot 0$ & 15 & Slit $1.0 \mathrm{~cm}$. \\
\hline 4 & 34 & $\mathrm{~F}$ & M.S. (M.I.), P. H. & .. & A.F. & $88 / 50$ & $92 / 48$ & 25 & $3 \cdot 7$ & 9 & Slit $1.0 \mathrm{~cm}$. \\
\hline 5 & 27 & $\mathrm{~F}$ & M.S. (A.I.), P. H. & .. & N. & $90 / 50$ & $55 / 30$ & 20 & $4 \cdot 7$ & $3 \cdot 5$ & $0.5 \mathrm{~cm}$. long \\
\hline 6 & 33 & M & M.S. (M.I.), P. H. & .. & A.F. & $120 / 70$ & $50 / 27$ & - & $4 \cdot 8$ & - & Slit $2.0 \mathrm{~cm}$. \\
\hline 7 & 19 & $\mathbf{F}$ & M.S. severe & . . & N. & $100 / 70$ & - & 30 & - & - & 0.6 by $0.3 \mathrm{~cm}$. \\
\hline 8 & 28 & $\mathrm{~F}$ & M.S. (A.I.) & $\ldots$ & N. & $105 / 55$ & $40 / 20$ & 20 & $5 \cdot 5$ & 2 & 0.75 by $0.5 \mathrm{~cm}$ \\
\hline 9 & 30 & $\mathbf{M}$ & M.S., P. H. & & N. & $90 / 60$ & $75 / 40$ & 18 & $3 \cdot 5$ & 10 & 1.0 by $0.5 \mathrm{~cm}$ \\
\hline 10 & 32 & $\mathrm{~F}$ & M.S. (?A.I.)* & 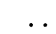 & N. & $140 / 100$ & $35 / 12$ & 12 & $2 \cdot 5$ & $3 \cdot 5$ & Not known \\
\hline 11 & 26 & $\mathrm{~F}$ & M.S. severe & .. & N. & $95 / 60$ & $43 / 18$ & 20 & $2 \cdot 6$ & $4 \cdot 6$ & 0.75 by $0.25 \mathrm{~cm}$ \\
\hline 12 & 30 & $\mathrm{~F}$ & M.S.* & & N. & $120 / 75$ & $16 / 3$ & 5 & $4 \cdot 3$ & 1 & Not known \\
\hline 13 & 36 & $\mathrm{~F}$ & M.S. (?A.I.) & & N. & - & \multirow{3}{*}{\multicolumn{3}{|c|}{$\begin{array}{l}\text { No catheter } \\
\text { No catheter } \\
\text { No catheter }\end{array}$}} & & \\
\hline 14 & 31 & $\mathrm{~F}$ & M.S. & & N. & - & & & & & \\
\hline 15 & 33 & $\mathbf{M}$ & M.S., M.I., P. H. & & A.F. & $170 / 105$ & & & & & $0.6 \mathrm{~cm}$. diam. \\
\hline 16 & 35 & $F$ & M.S., P. H.* & & A.F. & $100 / 60$ & $35 / 12$ & 10 & $2 \cdot 8$ & 6 & \\
\hline 17 & 34 & $\mathbf{M}$ & M.S. (A.S., A.I.) & & N. & $95 / 65$ & $62 / 25$ & 25 & $4 \cdot$ & $4 \cdot 3$ & \\
\hline 18 & 36 & $\mathrm{~F}$ & M.S. (A.I.) & & N. & $120 / 80$ & $50 / 32$ & 24 & $5 \cdot 0$ & $3 \cdot 2$ & \\
\hline 19 & 27 & $\mathrm{~F}$ & M.S. A. & & N. & $150 / 75$ & \multirow{2}{*}{\multicolumn{3}{|c|}{$\begin{array}{l}\text { No catheter } \\
\text { No catheter }\end{array}$}} & & \\
\hline 20 & 19 & $\mathbf{M}$ & M.S. A.I. (T.S., P.S.) & & N. & $120 / 90$ & & & & & Less than tip of \\
\hline 21 & 23 & $\mathrm{~F}$ & M.S., P. H. & .. & N. & $135 / 80$ & $100 / 45$ & 12 & $3 \cdot 7$ & 13 & 0.8 by $0.4 \mathrm{~cm}$ \\
\hline
\end{tabular}

N. Normal sinus rhythm. A.F. Auricular fibrillation. P.H. Pulmonary Hypertension. Pressures in $\mathrm{mm}$. Hg. Cardiac output in $1 . / \mathrm{min}$. Pulmonary resistance in arbitrary units. * These patients had a tendency to faint on exertion.

Generalized cardiac enlargement on radiological examination was not characteristic, and was noted in only four patients. In two the heart was considered to be small. The right ventricle appeared to be enlarged in twelve patients, and the main pulmonary artery in ten. The electrocardiogram showed various degrees of right ventricular preponderance in thirteen patients, and was normal or balanced in the remainder.

Seven patients had severe pulmonary hypertension, with a high pulmonary resistance and a low cardiac output at rest. Of eight other patients who were catheterized, the cardiac output was low in six and within normal limits in only two. Very low figures for the cardiac output were found both among those with and without pulmonary hypertension.

No direct measurements of cardiac output on exertion were made, but in six patients changes in the pulmonary artery and pulmonary capillary pressures were observed during exercise. If pulmonary capillary pressure is taken to represent left atrial pressure (Epps and Adler, 1953) and if the pulmonary resistance remains constant (Gorlin et al., 1951), the cardiac output on exertion may be calculated from the equation:

$$
\text { Pulmonary resistance }(\text { units })=\frac{\text { P.A. pressure }- \text { L.A. pressure }(\mathrm{mm} . \mathrm{Hg})}{\text { Cardiac output }(1 . / \mathrm{min} .)}
$$


In five of the six patients the cardiac output so calculated showed an increase from the resting level of less than 50 per cent.

The size of the stenosed mitral orifice was estimated at operation or at necropsy in 13 patients. The area was estimated to be less than $0.5 \mathrm{sq} . \mathrm{cm}$. in 11 and about $1 \mathrm{sq} . \mathrm{cm}$. in the remaining two. Angina pectoris was completely relieved after operation in all cases.

The occurrence of angina pectoris in patients with mitral stenosis could thus be correlated with (1) the severity of the stenosis, as judged clinically or as estimated at operation or at necropsy; and (2) low cardiac output at catheterization, (suggested clinically by a pulse of small volume, low systemic blood pressures, and cold vasoconstricted extremities) which was associated with severe mitral stenosis or severe pulmonary hypertension or both.

\section{Other Rheumatic Valvular Lesions}

One hundred consecutive patients with predominant aortic incompetence were reviewed for the occurrence of angina pectoris. The aortic valve lesion was considered to be of rheumatic origin in all, and any involvement of the mitral valve was judged to be slight. Those with systemic hypertension were excluded, as were patients with syphilitic aortitis or valvulitis. Nine patients suffering from angina pectoris were found, and their age incidence corresponded closely with that of uncomplicated coronary heart disease, the youngest being 49 years of age.

Among 40 patients with pure mitral incompetence presumably of rheumatic origin there were none suffering from angina pectoris. Tricuspid valve stenosis was thought to be the predominant lesion in one patient, a woman aged 40 years, who had suffered from angina of effort for three years. Unfortunately the clinical diagnosis was not proven by catheterization or necropsy.

The common association of angina pectoris with aortic stenosis is well known. Rheumatic aortic stenosis is often combined with a lesion of the mitral valve. Isolated aortic stenosis in young subjects was considered to be more often congenital in origin, and these patients are considered in the next section.

\section{Congenital Heart Disease}

The same criteria for the diagnosis of angina pectoris and the same age limits were used as for the patients with mitral stenosis. There were 448 consecutive patients with a congenital heart lesion available for review, and there were an additional 26 patients with isolated aortic or subaortic stenosis in whom the murmur had been discovered in infancy or early childhood and who showed no evidence of rheumatic disease. Many of the latter group were included in the series reported by Campbell and Kauntze (1953). Six patients suffering from primary pulmonary hypertension were also included.

Angina pectoris occurred in $23(4 \cdot 8 \%)$, and these patients fell into three main groups.

(1) Aortic stenosis (6 of 26 patients).

(2) Severe pulmonary stenosis (6 of 38 patients).

(3) Pulmonary hypertension, either primary (2 of 6 patients), of complicating a shunt with left to right blood flow or with a balanced circulation (6 of 24 patients.)

In the remaining three patients with angina pectoris the diagnosis was not established with certainty despite full investigation, but two of them probably suffered from infundibular pulmonary stenosis with reversed inter-atrial shunt, and the third from pulmonary hypertension complicating an atrial septal defect. There was no history of angina in 183 patients with uncomplicated left-toright shunts, in 79 patients with mild or moderate pulmonary stenosis, in 30 patients with reversed shunts due to severe pulmonary hypertension, and in 83 patients with morbus coeruleus (mostly Fallot's tetralogy).

Some of the findings in the twenty patients with angina pectoris in whom an exact diagnosis was made are shown in Table III. Overwhelming female preponderance was found amongst those with pulmonary hypertension (Wood, 1952). The pulse was of small volume in fifteen patients and the systemic blood pressures were mostly in the low normal range. Hæmoglobin values were 
normal or raised. It is interesting to note the value of 140 per cent in Case 10, a patient with severe infundibular stenosis as an isolated lesion proven at necropsy. Similar high hæmoglobin values have been found in some patients with primary pulmonary hypertension (Wood, 1952). Generalized cardiac enlargement of more than slight degree was found on radiological examination in only three patients, and there were no characteristic changes in the electrocardiogram at rest.

TABLE III

Patients with Anginä Pectoris and Congenital Heart Disease

\begin{tabular}{|c|c|c|c|c|c|c|c|c|c|c|c|}
\hline $\begin{array}{l}\text { Case } \\
\text { No. }\end{array}$ & Age & Sex & Diagnosis & Pulse & $\begin{array}{l}\text { Systemic } \\
\text { B.P. }\end{array}$ & Hb. & $\begin{array}{l}\text { R.V. } \\
\text { pres- } \\
\text { sures }\end{array}$ & $\begin{array}{l}\text { P.A. } \\
\text { pres- } \\
\text { sures }\end{array}$ & $\begin{array}{l}\text { Cardiac } \\
\text { output }\end{array}$ & $\begin{array}{l}\text { Resist- } \\
\text { ance }\end{array}$ & $\begin{array}{l}\text { Arterial } \\
\mathrm{O}_{2} \underset{\%}{\%}\end{array}$ \\
\hline 1 & 27 & $\mathbf{F}$ & Primary pulmonary & & & & & & & & \\
\hline 2 & 24 & & $\begin{array}{ll}\text { hypertension* } & \cdots\end{array}$ & Small & $105 / 80$ & $13 \cdot 3$ & $108 / 6$ & $117 / 60$ & $4 \cdot 3$ & 20 & 95 \\
\hline & & & hypertension* & Small & $100 / 80$ & $13 \cdot 1$ & 50 & 63 & $5 \cdot 3$ & 12 & 93 \\
\hline 3 & 31 & $\mathbf{F}$ & $\begin{array}{l}\text { P.D.A. and pulmonary } \\
\text { hypertension* }\end{array}$ & Normal & $120 / 70$ & $14 \cdot 0$ & $130 / 5$ & 85 & $4 \cdot 0$ & 21 & 85 \\
\hline 4 & 23 & $\mathrm{~F}$ & $\begin{array}{l}\text { P.D.A. and pulmonary } \\
\text { hypertension* }\end{array}$ & & $135 / 60$ & $12 \cdot 0$ & 年 & 66 & - & - & 95 \\
\hline 5 & 13 & F & $\begin{array}{l}\text { P.D.A. and pulmonary } \\
\text { hypertension }\end{array}$ & Normal & $120 / 65$ & $15 \cdot 4$ & $115 / 2$ & $115 / 75$ & - & $>13$ & 83 \\
\hline 6 & 30 & $\mathbf{F}$ & $\begin{array}{l}\text { A.S.D. and pulmonary } \\
\text { hypertension }\end{array}$ & Small & $105 / 65$ & $17 \cdot 5$ & $100 / 0$ & $100 / 55$ & $2 \cdot 7$ & 12 & 95 \\
\hline 7 & 28 & F & $\begin{array}{l}\text { A.S.D. and pulmonary } \\
\text { hypertension* }\end{array}$ & Small & $100 / 75$ & $18 \cdot 2$ & 30 & & $2 \cdot 5$ & 11 & 88 \\
\hline 8 & 33 & F & $\begin{array}{l}\text { A.S.D. and pulmonary } \\
\text { hypertension }\end{array}$ & Small & $115 / 85$ & $14 \cdot 7$ & & 72 & $3 \cdot 5$ & 20 & 84 \\
\hline 9 & 27 & $\mathrm{~F}$ & Pulmonary valve stenosis & Small & $118 / 60$ & $80 \%$ & $175 / 3$ & 2 & $<4 \cdot 0$ & - & 95 \\
\hline 10 & 23 & F & Pulmonary valve stenosis & Small & $120 / 80$ & & \multicolumn{5}{|c|}{ Not catheterized } \\
\hline $\begin{array}{l}11 \\
12\end{array}$ & 20 & M & Infundibular stenosis & Small & $110 / 50$ & $140 \%$ & $15(?)$ & 5 & $1 \cdot 6$ & - & 94 \\
\hline $\begin{array}{l}12 \\
13\end{array}$ & 28 & $\mathbf{M}$ & Infundibular stenosis* & $\ldots$ & $90 / 55$ & $105 \%$ & $60 / 4$ & $21 / 1$ & $4 \cdot 6$ & 一 & 92 \\
\hline & 20 & $\mathbf{F}$ & $\begin{array}{l}\text { reversed inter-atrial } \\
\text { shunt* }\end{array}$ & Small & $130 / 90$ & $17 \cdot 5$ & $165 / 5$ & 2 & - & - & 82 \\
\hline 14 & 10 & $\mathbf{F}$ & $\begin{array}{l}\text { Pulmonary stenosis and } \\
\text { reversed inter-atrial } \\
\text { shunt }\end{array}$ & Small & $80 / 55$ & $13 \cdot 3$ & $125 / 15$ & $17 / 10$ & $2 \cdot 8$ & - & 82 \\
\hline 15 & 24 & $\mathbf{F}$ & Aortic stenosis .. & - & $120 / 90$ & - & & \multirow{6}{*}{\multicolumn{4}{|c|}{$\begin{array}{l}\text { Not catheterized } \\
\text { Not catheterized } \\
\text { Not catheterized } \\
\text { Not catheterized } \\
\text { Not catheterized } \\
\text { Not catheterized }\end{array}$}} \\
\hline 16 & 14 & M & Aortic stenosis .. & Small & $105 / 80$ & - & & & & & \\
\hline 17 & 18 & $\mathbf{M}$ & Aortic stenosis .. & Small & $130 / 90$ & - & & & & & \\
\hline 18 & 29 & $\mathbf{M}$ & Aortic stenosis :. & Small & $120 / 100$ & - & & & & & \\
\hline 19 & 27 & $\mathbf{F}$ & Subaortic stenosis & Small & - & - & & & & & \\
\hline 20 & 26 & $\mathbf{F}$ & Aortic stenosis .. & Small & $100 / 80$ & - & & & & & \\
\hline
\end{tabular}

Hæmoglobin values in g. per $100 \mathrm{ml}$, or as percentage of normal (Haldane). All pressures in millimetres of mercury. Cardiac output in litres per minute. Resistances in arbitrary units.

* These patients had a tendency to faint on exertion.

The arterial oxygen saturation was normal in eight patients and low (82-85\%) in five, presumably because of some right-to-left shunting. Much lower figures were of course found in patients with cyanotic forms of heart disease who did not have cardiac pain. The cardiac output at rest was low in seven of the nine patients in whom it was estimated. From observations during exercise in one patient the calculated cardiac output increased less than 20 per cent above the resting level.

Angina pectoris did not occur in patients with uncomplicated left-to-right shunts, with pulmonary stenosis of mild or moderate degree, or with most cyanotic forms of congenital heart disease. It is important to note the difference in incidence of angina pectoris in patients with left-to-right shunts with pulmonary hypertension, and in those with the same lesions complicated by severe pulmonary hypertension that had produced free blood flow from the right to the left side of the 
heart. In the latter group of patients levels of pulmonary blood pressure were higher, right ventricular work and right ventricular hypertrophy were greater, the size of the heart was increased, and levels of arterial oxygen saturation were lower; yet angina pectoris did not occur. The conclusion is that these features are not essential for the production of cardiac pain. It is suggested that the essential difference between these two groups is the establishment of the reversed shunt, whereby on exertion blood returning to the right side of the heart can be transferred more easily to the left side, and the cardiac output increased thereby in a relatively normal fashion. The obstruction (pulmonary arteriolar vasoconstriction or sclerosis) is by-passed by blood flowing in a reverse direction through the shunt. Similar reasoning may be applied to patients with severe pulmonary stenosis and with Fallot's tetralogy except that in the latter group dextraposition of the aorta is present as well as a septal defect which can act as a by-pass. In the other two groups with a high incidence of angina pectoris, namely primary pulmonary hypertension and aortic stenosis, the obstruction cannot normally be by-passed, but the possibility of making an artificial ductus arteriosus in the treatment of primary pulmonary hypertension has been considered (Wood, 1952).

There were two features common to the patients with cardiac pain; firstly, an obstruction to the circulation of the blood, either severe organic stenosis of the aortic valve, the pulmonary valve or infundibulum, or obstruction in the pulmonary arterial tree associated with pulmonary hypertension; and secondly, evidence of a low cardiac output both on clinical grounds and at catheterization.

\section{POST-MORTEM EXAMINATION}

The results of necropsy were available in eleven patients who had suffered from angina pectoris during life. Four had predominant mitral stenosis (Cases M.S. 1, 2, 15, and 20), two primary pulmonary hypertension (Cases C.H.D. 1 and 2), one severe infundibular stenosis (Case C.H.D. 11) and one severe aortic stenosis (Case C.H.D. 17). There were three additional patients who had suffered from angina pectoris, a woman, aged 33 years, with predominant mitral stenosis, and two men, aged 35 and 44 years, with severe aortic stenosis.

In all these patients at necropsy the coronary arteries appeared patent and normal, and the aorta showed little or no atheroma.

\section{The EleCtrocardiogram ON EXERCISE}

Scherf and Goldhammer (1933) reported changes in the electrocardiogram suggestive of myocardial ischæmia during an attack of anginal pain at rest in a woman with mitral stenosis. Howarth and Lowe (1953) published one record showing changes in lead V1 on exertion in a patient with primary pulmonary hypertension.

Exercise tests were carried out on 33 patients in all, using the method described by Wood et al. (1950) and examples are shown in Fig. 1-4. The record in Fig. 3 has been published in part by Wood (1954). The twelve standard leads were recorded in most instances, both at rest and after exercise. There were fifteen control patients, eleven with mitral stenosis and four with congenital heart disease, who did not suffer from angina pectoris. Non-specific changes noted in the electrocardiogram were increase in the amplitude of the $P$ and $T$ waves. Sometimes a $T$ wave that was flat or inverted at rest became upright on exertion. Two control patients showed slight changes suggestive of myocardial ischæmia on effort, of the type described below. One was a woman, aged 42 years, with both mitral and aortic stenosis, who did complain of tightness across the chest on hurrying, but had not been included among the positive cases because she insisted that it was not pain, and this had been used as a differential point. The other patient had severe pulmonary infundibular stenosis with a right ventricular systolic pressure of $100 \mathrm{~mm}$. $\mathrm{Hg}$ and a cardiac output of $3 \cdot 3$ litres a minute at rest.

There were 18 patients who suffered from angina pectoris, 5 with mitral stenosis and 13 with 


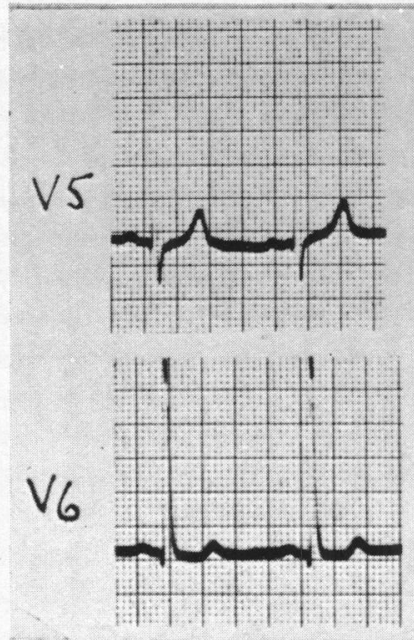

A
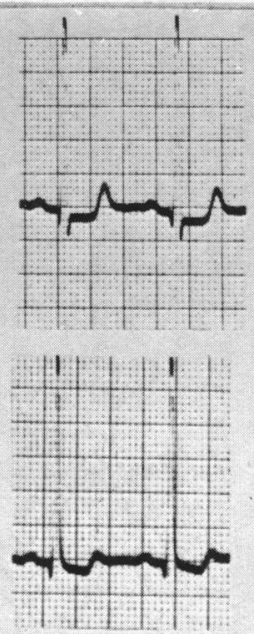

B
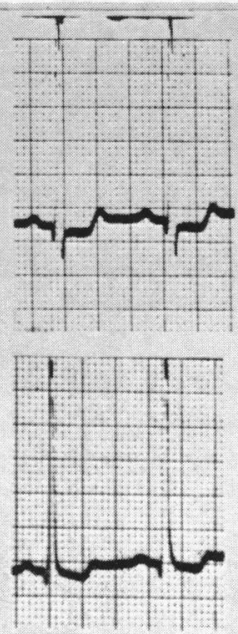

C
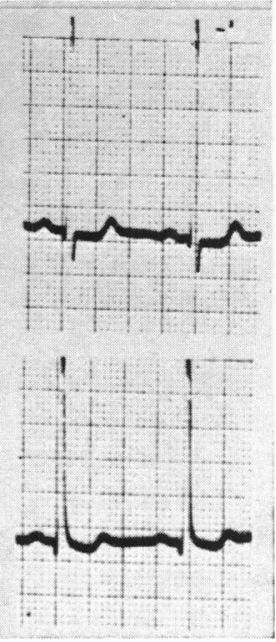

D

FIG. 1.-Exercise test in a man, aged 42 years, with aortic stenosis who had suffered from angina pectoris for ten years. (A) At rest. (B) During exercise. There was well-marked flat depression of the S-T segment in leads V5 and V6 with diminution or obliteration of the $T$ wave, best seen in (C) taken 5 minutes after exercise, which produced anginal pain lasting 3 minutes in this patient. (D) Ten minutes after exercise.

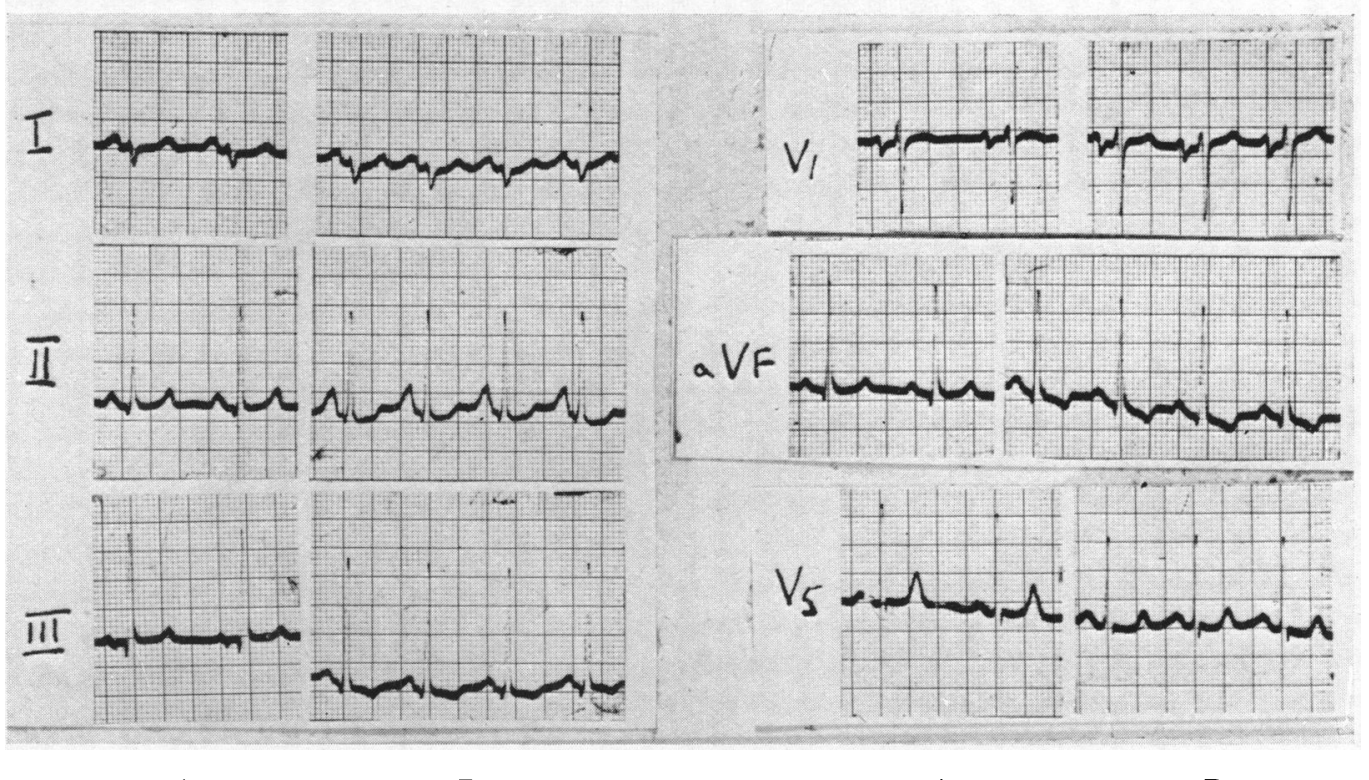

A

B

A

B

FIG. 2.-Exercise test in Case M.S. 10, a woman, aged 32 years, with angina pectoris and mitral stenosis. Slight aortic incompetence was present but no pulmonary hypertension. (A) At rest. (B) After exercise. There was slight sagging of the S-T segment with considerable reduction in the height of the T wave in leads V4 and V5, the same changes being reflected more strongly with complete inversion of the T wave in leads aVF, III, and II. The T wave in lead V1 was more upright after exercise. The test produced transient faintness but no pain in this patient. Blood pressure levels showed no significant alteration. 


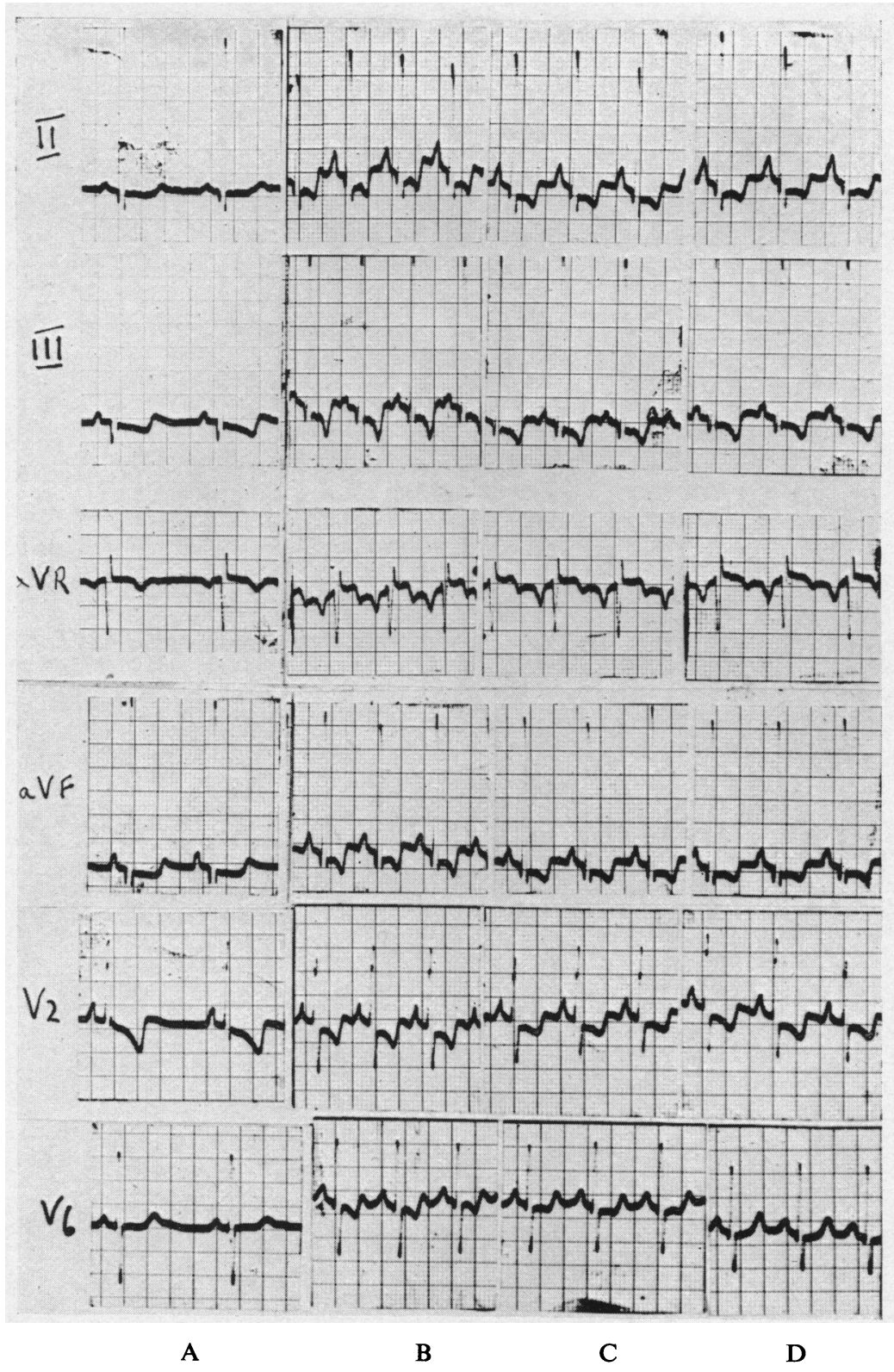

FIG. 3.-Exercise test in Case M.S. 21, a woman, aged 23 years, with mitral stenosis and severe pulmonary hypertension who suffered from angina pectoris. (A) Resting. (B) Two minutes, (C) 4 minutes, and (D) 6 minutes after exercise. There was flat elevation of the S-T segment and obliteration of the normally inverted $T$ wave in lead aVR best seen at 4 minutes after exercise, and depression of the S-T segment and deep $\mathbf{T}$ wave inversion in leads II, III, and aVF. The pattern in these leads was abnormal at rest, making interpretation of the changes difficult. There was depression of the S-T segment and partial inversion of the $T$ wave at 2 minutes and 4 minutes in lead V6, the only left ventricular surface lead, with return to the normal resting pattern at 6 minutes. There was less inversion of the $T$ wave in lead V2 after exercise than at rest. The test produced anginal pain in this patient. 
congenital heart disease. On exercise, changes in the cardiogram consistent with myocardial ischæmia were found in 7, suggestive changes of lesser degree in 5 , and no significant change in 6 patients. All the latter had grossly abnormal records at rest, and this made it difficult or impossible to recognize significant changes after exercise.

Changes in the cardiogram indicating mycardial ischæmia were best seen in leads II, III, and aVF, and in left ventricular surface leads (V4-V7), even in patients with marked right ventricular preponderance in the cardiogram. Elevation of the S-T segment and obliteration of the normally inverted $T$ wave in lead aVR may also be an ischæmic pattern. In right ventricular surface leads the tendency was for $T$ waves previously inverted to become upright after exercise, and for the $S-T$ segment to move in the same direction (Fig. 4); these changes were found in seven patients with marked right ventricular preponderance in the cardiogram at rest.

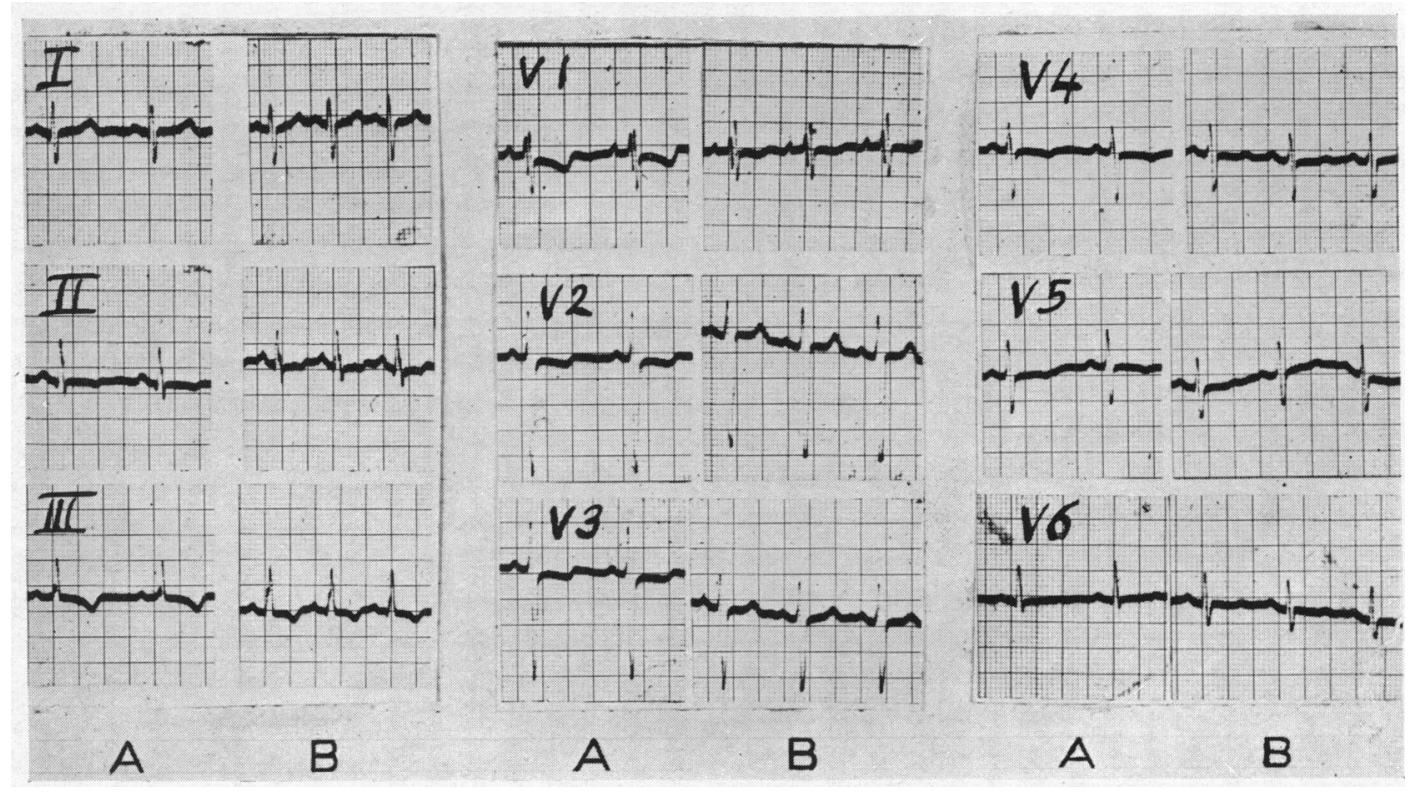

FIG. 4.-Exercises test in a woman, aged 47 years, who had suffered from primary pulmonary hypertension and angina pectoris. (A) Resting. (B) After exercise. There was slight S-T depression in lead II on effort. The $\mathrm{T}$ waves in leads V1-V5 inverted at rest became upright after exercise, and the S-T segments depressed at rest were isoelectric on exertion. Similar changes were found in right ventricular surface leads in a number of patients with angina pectoris and conditions associated with marked right ventricular preponderance, but did not occur in the controls. There is no true left ventricular lead shown: perhaps lead $\mathrm{V} 7$ or $\mathrm{V} 8$ would have been more useful.

In two patients in whom well-marked changes in the cardiogram occurred on exertion, trinitrin was given in full dosage before exercise. Exactly the same ischæmic changes were seen on exercise, and these took longer to disappear with rest. The blood pressure was estimated by the cuff method in eight patients before and after exercise sufficient to induce anginal pain, and the pressures after exercise were always at or above the resting level.

\section{Discussion}

The ages of the patients discussed in this paper make it unlikely that coronary artery disease played a significant part in producing cardiac pain. This was confirmed by the absence of evidence of coronary artery disease in eleven patients at necropsy. Undoubtedly in older patients with less 
severe mitral or aortic stenosis, coronary atherosclerosis may coexist and may play a contributory part in causing myocardial ischæmia on exertion.

Low arterial oxygen saturation with accompanying central cyanosis does not seem to be an important factor in producing cardiac pain. Most of the patients with angina pectoris had a normal arterial oxygen saturation, and in the six with potentially reversible shunts, the arterial oxygen saturation was 82 per cent or more at rest. Angina pectoris was not encountered among 83 patients with cyanotic forms of congenital heart disease nor among 30 with severe pulmonary hypertension and reversed shunts. The term hypercyanotic angina is best restricted to the group originally described by Vaquez and Giroux (1908).

Increased mass of cardiac muscle is probably not an important factor. Generalized cardiac enlargement of more than slight degree on radiological examination was uncommon in the patients with cardiac pain. In a number of them the heart appeared to be well within normal limits for size.

Evidence has been presented that myocardial ischæmia occurs on exertion in these patients with angina pectoris, and that the ischæmic changes in the electrocardiogram are best seen in left ventricular surface leads even in patients with marked right ventricular hypertrophy. Cardiac pain and rather similar changes in the cardiogram occur in patients with massive pulmonary embolism (Currens, 1942; Wood, 1948), and it is interesting to compare the myocardial lesions post mortem in this condition (Dack et al., 1949; Currens and Barnes, 1943) and in aortic stenosis (Friedberg and Horn, 1939). In both conditions the myocardial lesions were subendocardial, focal, and disseminated, and greater in the left ventricle than in the right. The suggestion is that, in these conditions and in the patients discussed in this paper, those parts of the myocardium at the periphery of the normal coronary arterial tree and furthest removed from the source of blood supply will be affected by ischæmia first and most severely. The left ventricle would thus suffer as much as the right ventricle.

The important correlation of cardiac pain in patients with mitral stenosis or congenital heart disease is with a low cardiac output. It has been shown by a number of observers (Bayliss et al., 1950; Draper et al., 1951; Ball et al., 1952) that in patients with severe mitral stenosis the cardiac output is low at rest and does not approach normal levels on exertion. The same probably applies to severe grades of aortic stenosis, pulmonary stenosis, and pulmonary hypertension. The coronary blood flow normally constitutes 4-5 per cent of the cardiac output at rest (Gregg, 1950), and the proportion may rise to 12-15 per cent after exercise, after administration of adrenaline, or in shock (Eckenhoff et al., 1947). It is probable that this figure approaches the maximum proportion of the cardiac output that can be diverted into the coronary arterial tree while other essential parts of the circulation are maintained. When the cardiac output cannot increase adequately on exertion, the coronary blood flow may be too small for the demands of the myocardium, especially when the cardiac work is greatly increased by an obstruction to the circulation. The increased cardiac work involved for instance in aortic stenosis has been pointed out by Evans (1918).

The basic pathological condition in these patients is thus an obstruction to the circulation. This may be either an organic stenosis of the aortic, mitral, pulmonary, or tricuspid valves or of the infundibulum of the right ventricle, or obstruction in the pulmonary circuit associated with severe pulmonary hypertension (pulmonary arteriolar vasoconstriction or sclerosis).

In many of the patients discussed in this paper two or more obstructive lesions were present, for example, among those with mitral stenosis there was pulmonary hypertension in 6 cases, aortic stenosis in one, and tricuspid stenosis in two, one of these having pulmonary hypertension as well and the other pulmonary stenosis as well (see Table II). The effect of such multiple obstructions to the circulation of the blood on the ability of the cardiac output to increase normally on exertion is probably additive.

The patients described in this paper could be included in the all-embracing term "coronary insufficiency" as used by Masters and others, but in themselves form a compact clinical group with identical functional disturbance and well-known basic pathology, and so merit separate description. 


\section{SUMMARY AND CONCLUSIONS}

Of 400 patients suffering from mitral stenosis, angina pectoris (angina of effort) occurred in 34 $(8.5 \%)$, of whom 21 were aged under 37 years in the case of women, and under 35 years in the case of men. Of these 21 patients, seven had marked pulmonary hypertension and in the remainder the mitral stenosis was severe.

Among 480 cases of congenital heart disease, angina pectoris occurred in 23 patients under the age limits mentioned $(4.8 \%)$. These fell into three main groups; aortic stenosis, severe pulmonary stenosis, and pulmonary hypertension, either primary or complicating a left-to-right or balanced shunt.

There was no evidence of coronary artery disease post mortem in eleven of these patients with mitral stenosis or congenital heart disease who had suffered from angina pectoris during life.

Exercise tests were carried out on 33 patients. Changes in the electrocardiogram on exercise indicating myocardial ischæmia were found in 12 of 18 patients with angina pectoris, and slight changes in only 2 of 15 controls. The changes were best seen in left ventricular surface leads even in the presence of predominant right ventricular hypertrophy.

A mechanical obstruction to the circulation of the blood is present in all these conditions, either within the heart or in the pulmonary circulation. This is responsible for a low fixed cardiac output that does not increase adequately on exertion. It is suggested that inadequate coronary blood flow during exercise is a result of the low cardiac output.

Cardiac pain occurring in young subjects with rheumatic or congenital heart disease suggests an obstructive lesion, and is an index of severity in those with aortic, mitral, or pulmonary stenosis.

Thanks are due to members of the visiting staff of the National Heart Hospital for allowing the author to study patients under their care, and in particular to Dr. Paul Wood, Director of the Institute of Cardology, for giving access to some of his own private material, and for advice, criticism, and encouragement.

This paper is part of a thesis presented for the degree of Doctor of Medicine in the University of Sydney.

\section{REFERENCES}

Abrahams, D. G., and Wood, P. H. (1952). Brit. Heart J., 13, 419.

Arillaga, F. C. (1913). Arch. Mal. Coeur, 6, 518.

Astley, R., and Parsons, C. (1952). Brit. Heart J., 14, 13.

Ball, J. D., Kopelman, H., and Witham, A. C. (1952) Brit. Heart J., 14, 363.

Bayliss, R. I. S., Etheridge, M. J., and Hyman, A. L. (1950). Lancet, 259, 889.

Bedford, D. E., Papp, C., and Parkinson, J. (1941). Brit. Heart J., 3, 37.

Blackford, L. M. (1930). Arch. intern. Med., 45, 631.

- (1940). Amer. Heart J., 20, 492.

Brenner, O. (1935). Arch. intern. Med., 56, 724.

Brill, I. C., and Krygier, J. J. (1941) Arch. intern. Med., 68, 560.

Burgess, A. M. Jr., and Ellis, L. B. (1942). New England J. Med., 226, 937.

Campbell, M., and Kauntze, R. (1953). Brit. Heart J., 15, 179.

-

Currens, J. (1942). Proc. Staff Mayo Clinic, 17, 502.

- and Barnes, A. R. (1943). Arch. intern. Med., 71, 325.

Dack, S., Master, A. M., Horne, H., Grishman, A., and Field, L. E. (1949). Amer. J. Med., 7, 464.

Dexter, L., Whittenberger, J. W., Haynes, F. W., Goodale, W. T., Gorlin, R., and Sawyer, C. G. (1951), J. Applied Physiol., 3, 439.

Draper, A., Heimbecker, R., Daley, R., Carroll, D., Mudd, G., Wells, R., Falholt, W., Andrus, E. C. and Bing, R. J. (1951). Circulation, 3, 531.

Dow, J. W., Levine, H. D., Elkin, M., Haynes, F. W., Hellems, H. K., Whittenberger, J. W., Ferris, B. G., Goodale, W. T., Harvey, W. P., Eppinger, E. C., and Dexter, L. (1950). Circulation, 1, 267.

Eckenhoff, J. E., Hafkenschiel, J. H., and Landmesser, C. M. (1947). Amer. J. Physiol., $149,634$.

Engelen, P. (1923). Deutsche med. Wochenschr., 49, 1015.

Epps, R. G., and Adler, R. (1953). Brit. Heart J., 15, 298.

Evans, C. L. (1918). J. Physiol., 52, 6.

Friedberg, C. K. (1949). Diseases of the Heart. Saunders and Co., p. 607.

- and Horn, H. (1939). J. Amer. med. Assn., 112, 1675.

Frugoni. (1911). Med. Nuova Roma, 2, 347.

Gorlin, R., Lewis, B. M., Haynes, F. W., Spiegl, R. J., and Dexter, L. (1951). Amer. Heart J., 41, 834.

Graham Steel. (1906). A Textbook of Diseases of the Heart. Philadelphia. p. 227.

Gregg, D. E. (1950). Coronary Circulation in Health and Disease. Kimpton, London, p. 133. 
Hirschfelder, A. D. (1910). Diseases of the Heart and Aorta. Lippencott, Philadelphia and London.

Hochrein, M. (1930). Deutsches Arch. klin. Med., 169, 195.

Howarth, S., and Lowe, J. B. (1953). Brit. Heart J., $15,47$.

Levine, S. A., and Kauvar, A. J. (1942). J. Mt. Sinai Hosp., 8, 754.

Lowance, M. I., Jones, E. C., Mathews, W. B., and Dunstan, E. M., (1948). Amer. Heart J., $35,820$.

Nothnagel, H. (1891). Ztschr. klin. Med., 19, 209.

Parker, F. Jr., and Weiss, S. (1936), Amer. J. Path., 12, 573.

Posselt, A. (1908). München-med. Wochenschr., 55, 1625.

Scherf, D., and Goldhammer, S. (1933). Ztschr. klin. Med., 124, 111.

Schwartz, S. P. (1927). Amer. Heart J., 2, 497.

Sternberg, M. (1923). Ztschr. klin. Med., 97, 110.

Stuckey, D. (1955). Med. J. Aust., 1, 169.

Telia, L. (1925). Arch. Mal du Coeur, 18, 531.

Vaquez, H., and Giroux, L. (1908). Bull. Mem. Soc. med. hôp., Paris, 25, 183.

Viar, W. N., and Harrison, T. R. (1952) Circulation, 5, 1.

White, P. D., and Mudd, S. G. (1927). Amer. Heart J., 3, 1.

Wood, P. (1948). Brit. Heart J., 10, 87.

- (1950). Brit. med. J., 2, 639.

- (1952). Brit. med. Bull., 8, 348.

- (1954). Brit. med. J., 1, 1051.

—, McGregor, M., Magidson, O., and Whittaker, W. (1950). Brit. Heart J., 12, 363. 